\title{
Primary pulmonary tumours of neurogenic origin
}

\author{
GIANCARLO ROVIARO, MARCO MONTORSI, FEDERICO VAROLI, RINO BINDA, \\ ATTILIO CECCHETTO
}

From Surgical Clinic II, University of Milan, and the Institute of Pathology, University of Padua, Italy

ABSTRACT Primary intrapulmonary neurogenic tumours are extremely rare. In a series of 1664 patients with pulmonary neoplasms observed during 1967-80 only four such tumours were identified $(0 \cdot 2 \%)$. All four patients underwent surgical excision. The histological diagnosis was benign neurilemmoma in three cases and malignant schwannoma in the fourth. The patients with neurilemmoma are alive and well four to 12 years after surgery, but the patient with malignant $ᄋ$ schwannoma died from metastatic spread of the tumour four months after surgery. No association with von Recklinghausen's disease was observed. Macroscopic and microscopic features generally lead to a correct diagnosis in benign types, but the histological diagnosis of malignant $\stackrel{\varnothing}{\varnothing}$ schwannoma may present some difficulties and requires the establishment of a definite origin in a nervous structure, identification of benign neurofibroma in different areas of the same tumour, $\mathbb{\Phi}$ and a high density of cells with appreciable pleomorphism, with mitosis and atypia. Benign $\overrightarrow{0}$ tumours carry a good prognosis with little tendency to recur, but malignant schwannoma has a high invasive tendency and is associated with a low survival rate.

Primary pulmonary tumours of neurogenic origin are extremely rare $^{1}$ and since the first case was reported by Rubin and Aronson in $1940^{2}$ only 50 cases have been described in published reports. Ten of these were classified as malignant. Review of the reports excluded some of these cases because of inadequate histological evidence. ${ }^{34}$

From March 1967 to December 19801664 patients with pulmonary neoplasms were observed at our institute. The vast majority of tumours were epithelial in origin but four $(0.2 \%)$ were primary neurogenic tumours, of which one was malignant. In this paper we present the clinical and pathological details of these patients and review the reports that have been published.

\section{Case reports}

\section{CASE 1}

A man of 45 presented with a symptomless, rounded opacity in the posterior segment of the left lower lobe. Bronchoscopy showed normal airways, apart from reduced mobility of a segmental bronchus of the left lower lobe. Left lower lobectomy was per-

\footnotetext{
Address for reprint requests: Dr Giancarlo Roviaro, Clinica Chirurgica II, Ospedale San Paolo, Via A di Rudini 8, 20142 Milan, Italy.

formed. The excised lobe contained a $4 \times 5 \mathrm{~cm}$ greyish white, well encapsulated tumour, surrounded by normal parenchymal tissue. Histological examination showed an Antoni A type pulmonary neurilemmoma. The patient was discharged after an uneventful postoperative period and is well and free from symptoms 12 years after surgery.

\section{CASE 2}

A woman of 47 , a heavy smoker, had been treated $\stackrel{x}{x}$ at the age of 17 for tuberculosis of the left upper lobe by therapeutic pneumothorax. At the age of 46 she had a haemoptysis and a chest radiograph showed a shadow in the medial part of the left lower lobe. Bronchoscopy showed partial stenosis of the 옥 anteromedial segmental bronchus of the left lower $D$ lobe and diffuse chronic bronchitis. A left lower lobectomy was performed. The excised specimen $N$ contained an encapsulated, yellowish mass measuring $8 \times 10 \mathrm{~cm}$, which compressed the adjacent pul- $\stackrel{N}{\circ}$ monary parenchyma (fig 1). Histological examination showed an Antoni A type neurilemmoma. The postoperative period was uneventful and the patient 0 is alive and well seven years after surgery.

CASE 3

A man of 50, who had been treated for tuberculosis of the left upper lobe at the age of 19 , had a chest $\cong$ radiograph taken during a medical examination that 


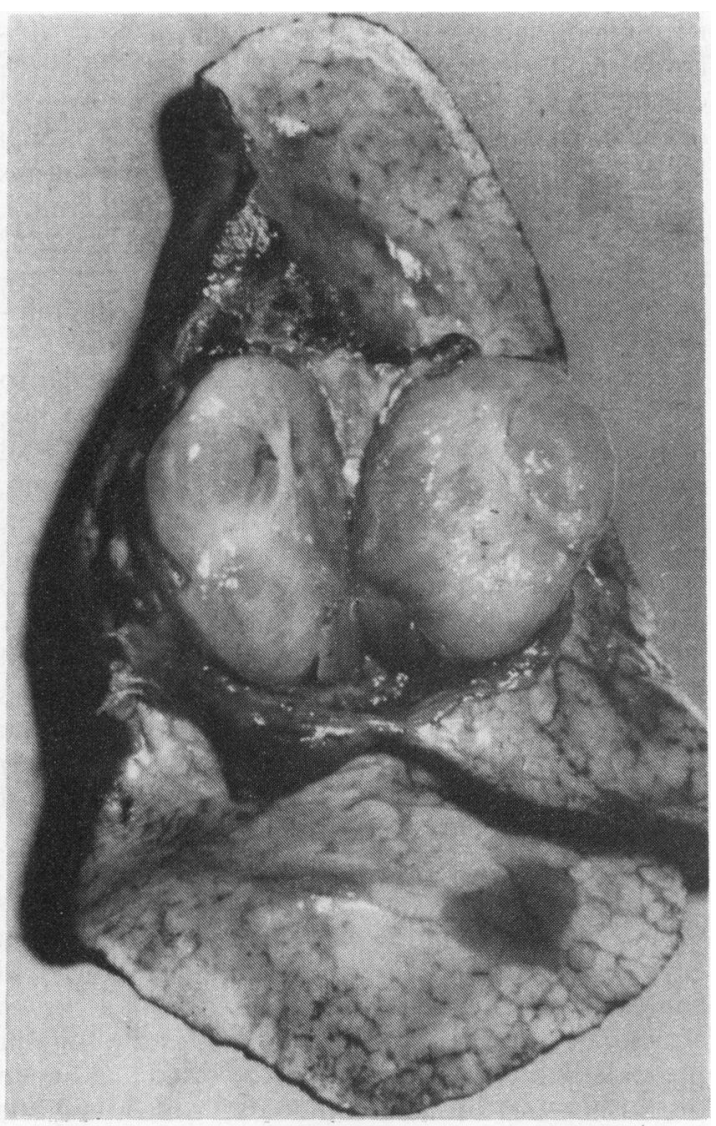

Fig 1 Case 2: Macroscopic appearance of the tumour, diagnosed as a neurilemmoma, Antoni A type.

showed a round mass affecting the lower aspect of the left hilum. Bronchoscopy showed compression and partial stenosis of the left lower bronchus a few millimetres from its origin. The apical segmental branch of the lower lobe bronchus was not visible. The patient underwent a left lower lobectomy. The specimen contained an encapsulated, greyish white mass measuring $6 \times 7 \mathrm{~cm}$, firmly adherent to but not infiltrating the inferior pulmonary vein and lower lobe bronchus. On the cut surface extensive areas of haemorrhage and necrosis were present. Histological examination showed an Antoni B type neurilemmoma. The patient made a good recovery and when last seen, four years after surgery, was well and free from symptoms.

\section{CASE 4}

A man of 27 had always enjoyed good health until he suddenly developed a fever, anorexia, weakness,

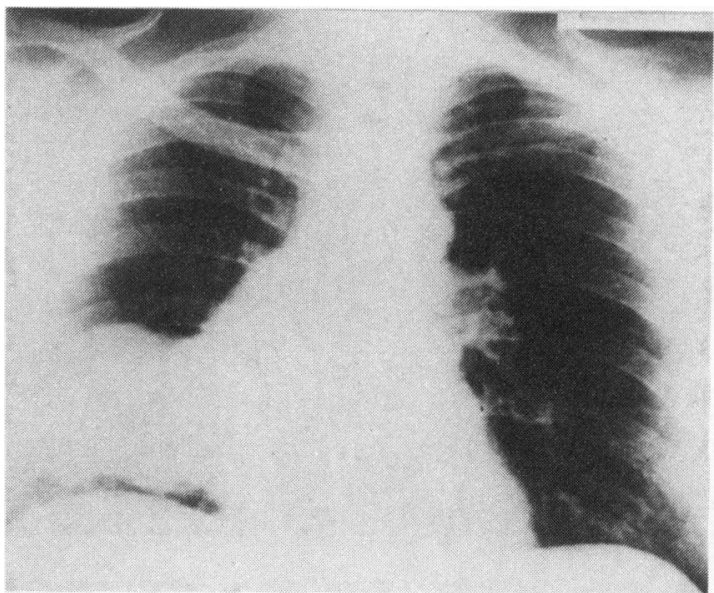

Fig 2 Case 4: Chest radiograph showing a polycyclic, well defined mass situated in the anterior planes of the lower third of the right lung, extending medially towards the pulmonary hilum and mediastinum.

and retrosternal pain. All laboratory tests gave normal results except for the erythrocyte sedimentation rate (ESR), which was $80 \mathrm{~mm}$ in one hour. A chest radiograph showed a nodular, well defined mass situated in the anterior lower third of the right lung (fig 2), extending medially toward the pulmonary hilum and mediastinum. Bronchoscopy showed uniform congestion of the bronchus intermedius and the middle and lower lobe bronchi and extrinsic upward displacement of the middle lobe bronchus. A soft mass filling the middle lobe and the anterior segments of the lower lobe was found at thoracotomy. Enlarged soft, bluish red hilar and mediastinal nodes were also present. The middle and lower lobes and mediastinal lymph nodes were excised. The mass measured $6 \times 11 \mathrm{~cm}$ and was greyish, with extensive areas of haemorrhage and necrosis on its cut surface. Adjacent to the middle lobe it was smooth and well encapsulated, whereas close to the lower lobe it was rough, friable, and greyish pink, with cystic and haemorrhagic areas. Histologically the tumour consisted of immature fusiform cells arranged in sheets and cords. Mitotic figures were frequent and cell borders indistinct (fig 3 ). In another area adjacent to the middle lobe the cells tended to form fascicles with a reticulin pattern resembling that of a neurofibroma. The definitive histological diagnosis was malignant schwannoma.

Although the postoperative course was uneventful, some weeks after discharge progressive weakness, weight loss, and caval obstruction occurred. Despite chemotherapy and radiotherapy the patient died four months after surgery. 


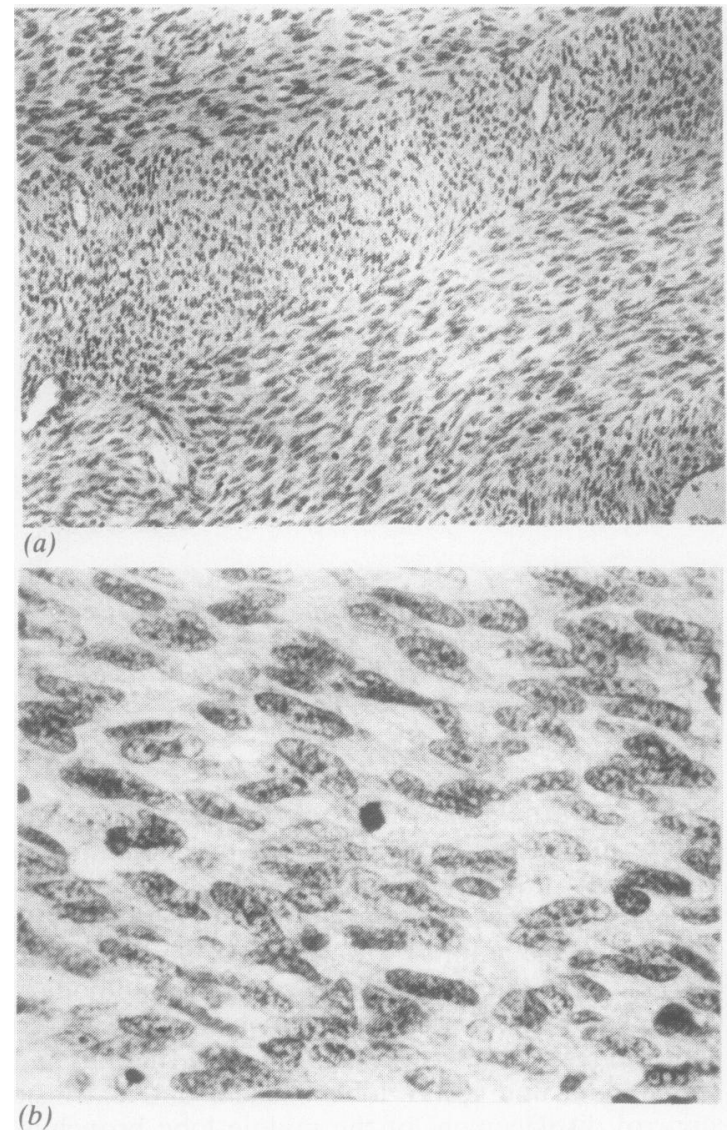

Fig 3 Case 4: Microscopic appearance of malignant schwannoma: $(a) \times 75 ;(b) \times 290$.

\section{Discussion}

Primary intrathoracic neurogenic tumours can originate anywhere in the thorax, but are most frequently found in the posterior mediastinum in the costovertebral angle. ${ }^{5}$ Intraparenchymal nerve tumours deriving from nerve fibres associated with the bronchial tree are exceedingly rare and in our series of 1664 pulmonary tumours they account for only $0.2 \%$.

Askanazy $^{6}$ first reported a neurofibroma of the bronchus associated with generalised neurofibromatosis in 1914. The first case to be described in detail was published by Rubin and Aronson in $1940 .^{2}$ Bartley and Arean ${ }^{4}$ in 1965 found that only 32 of the cases reported up to that time were genuine pulmonary neurogenic tumours. Oosterwijk and Swierenga ${ }^{7}$ reviewed the published reports again in 1970 and added three cases of their own.

Characteristically, primary benign intrapulmo- nary neoplasms are asymptomatic, most being discovered during routine radiography. Of the three cases we observed, two presented in this way and one patient had an episode of haemoptysis, which led to radiological investigation. Symptoms described in the published reports are usually mild, consisting of dry cough and some pleuritic pain, ${ }^{489}$ but Bartley reported a typical Pierre-Marie syndrome with joint pain and stiffness, which disappeared after removal of the tumour.

The symptoms of malignant lesions are similar to those of the more common carcinoma of the lung and include anorexia, weight loss, and fever or local symptoms such as thoracic pain, recurrent cough, and haemoptysis. In our fourth patient fever, malaise, anorexia, retrosternal pain, and the high ESR, with radiological evidence of a pulmonary mass, suggested a malignant lesion. In both malignant and benign tumours radiological and clinical features are non-specific and a correct diagnosis is usually made only after surgical exploration. Because of the position of these intrapulmonary tumours, resection of the lung tissue in which it occurs is always indicated.

Grossly benign neoplasms are encapsulated, sometimes lobulated masses of varied dimensions well demarcated from the surrounding tissue. When cut they are yellowish owing to the mucin and lipid content, firm, and solid. Multilocular cystic structures may also be seen. Sometimes the tumour presents as a mass bulging into the bronchial lumen or raising the bronchial mucosa, which may be ulcerated. ${ }^{4}$

Malignant neurogenic tumours are usually larger than the benign variety. Although distinct from the surrounding pulmonary parenchyma, they are never encapsulated. Their cut surfaces vary from grey to yellow, with areas of necrosis, haemorrhage, and cystic degeneration. Primary intrapulmonary neurogenic tumours may be divided histologically into neurofibroma and neurilemmoma; neurogenic sarcoma and malignant schwannoma are the malignant equivalents. Histological diagnosis is generally easy in the case of neurilemmoma and neurofibroma, but not always in the case of malignant schwannoma, which should be carefully dif- o ferentiated from other mesenchymal tumours such $N$ as fibrosarcoma and spindle cell anaplastic car- N్ల్ cinoma.

The tumour from the fourth patient meets the criteria for a neurogenic tumour as defined by Willis. ${ }^{10}$ A benign tumour (neurofibroma) could be $\stackrel{\mathscr{P}}{?}$ macroscopically and microscopically recognised in 0 an area adjacent to the middle lobe, whereas the capsule was absent in other parts of the tumour, strongly suggesting a malignant schwannoma. 
The association between primary neurogenic pulmonary tumours and von Recklinghausen's disease is well known. This syndrome, which is basically due to a defect in the development of Schwann cells, is characterised by the presence of multiple neurofibromas in the skin and internal organs. Ackerman and Taylor ${ }^{11}$ maintain that in such cases the proportion of malignant neurofibromas is very high, whereas others maintain that malignant mediastinal tumours are most likely to be malignant schwannomas. ${ }^{12}$ Schwannomas were reported by Stout ${ }^{13}$ to account for $18 \%$. There was no evidence of von Recklinghausen's disease in our patients.

In patients without von Recklinghausen's disease the prognosis of benign neurogenic tumours is good and there were no recurrences in the published cases. Our three patients are still alive and well four to 12 years after surgery. Malignant schwannoma, on the other hand, tends to recur and the survival rate is low. Although Neilson reported a malignant schwannoma in a 35 year old man who is still alive two years after surgery, death generally supervenes within a few weeks ${ }^{14}$ and our patient died four months after operation from metastatic spread.

\section{References}

' Schield TW. General thoracic surgery. Philadelphia: Lea and Febiger, 1972;11:846-58.

${ }^{2}$ Rubin EH, Aronson W. Primary neurofibroma of the lung. Am Rev Tuberc 1940;41:801-5.

${ }^{3}$ Neilson DB. Primary intrapulmonary neurogenic sarcoma. J Pathol Bacteriol 1958;76:419-30.

${ }^{4}$ Bartley TD, Arean VM. Intrapulmonary neurogenic tumors. J Thorac Cardiovasc Surg 1965;50:114-23.

5 Ingels GW, Cambell DC, Giampietro AM, Kozub RE, Bentlage $\mathrm{CH}$. Malignant schwannoma of the mediastinum. Cancer 1971;27:1190-3.

- Askanazy M. Cited by Neilson. ${ }^{3}$

' Oosterwijk AM, Swierenga J. Quelques cas de tumeurs neurogènes exceptionelles siégeant dans la cavité thoracique. Poumon Coeur 1970;26:571-88.

${ }^{8}$ Breton A, Gaudier B, Delacroix R, Dupont A, Poingt O. Neurinomes intra-pulmonaires primitifs. A propos de deux observations. Arch Franc Pédiat 1961;18:26-40.

${ }^{9}$ Soliani F. Neurinomi primitivi intrapolmonari. Policlinico (Sez Prat) 1959;66:51-55.

${ }^{10}$ Willis RA. Pathology of tumors. 2nd ed. London: Butterworth, 1953:644-55.

1 Ackerman LV, Taylor H. Neurogenous tumors within the thorax: a clinicopathological evaluation of 48 cases. Cancer 1951;4:669-91.

${ }^{12}$ Le Brigand $\mathrm{H}$. Le pronostic des tumeurs neurogènes endothoracique de la maladie de Recklinghausen. Ann Chir Thorac Cardiovasc 1977:16-20.

${ }^{13}$ Stout AP. The malignant tumors of the peripheral nerves. Am J Cancer 1935;25:36-41.

14 Weitzner S. Adjacent malignant schwannoma and neurofibroma of intrathoracic vagus. Am Surg 1976;42:866-70. 